\title{
A FILOSOFIA DOS JOVENS SOBRE O SER JOVEM: UMA PESQUISA SOCIOPOÉTICA
}

\author{
C. T. CARNEIRO ", F. S. CARVALHO, K. R. P. SANTOS, M. A. R. BEZERRA e S. J. H. C. ADAD \\ Universidade Federal do Piauí - UFPI \\ cristianneteixeira@hotmail.com*
}

Artigo submetido em janeiro/2014 e aceito em dezembro/2014

DOI: $10.15628 /$ holos.2014.1935

\section{RESUMO}

Objetivou-se conhecer os modos de pensar dos jovens de um curso técnico em enfermagem de um colégio técnico federal sobre "o que é ser jovem?". A pesquisa se insere no paradigma qualitativo de investigação utilizando a Sociopoética, foi realizada com onze jovens que cursavam o ensino médio concomitante ao técnico em enfermagem em 2013. Os jovens problematizaram a dimensão do tempo de espera para o mundo adulto, mostrando que não há um único modo de ser jovem e nem de se tornar adulto, pois para eles os ritos de passagem eram: casamento, saída da casa dos pais, o ingresso em um colégio técnico federal e o início dos estágios do curso técnico em enfermagem, demonstrando que esse momento não é fixo e nem demarcado. Eles também relataram jeitos de ser jovem em bandos que agem de modo diferente. Discutiram o tempo e a liberdade, ressaltando o quanto a rotina do jovem está relacionada à escola. Essa pesquisa possibilitou a oportunidade de reflexão sobre os conceitos sobre jovens, muitas vezes cristalizados numa sociedade que raramente leva em consideração a voz de quem mais entende sobre si mesmo, ou seja, do próprio sujeito que tem a experiência e vivencia a juventude.

PALAVRAS-CHAVE: Jovens, Colégio Técnico, Sociopoética.

\section{PHILOSOPHY OF YOUTH ON BEING YOUNG: A SOCIO-POETICS RESEARCH}

\begin{abstract}
It was aimed at to know the manners of thinking of the youths of a technical course in nursing of a federal technical school on "the one what is to be young?" The research interferes in the qualitative paradigm of investigation using Socio-poetics, it was accomplished with 11 young that studied the concomitant medium teaching to the technician in nursing in 2013, years. The youths problematized the dimension of the time of wait for the adult world, showing that no there is a single way of being young and nor of becoming adult, because for them the rites of passage were: marriage, exit of the parents' house, the entrance in a federal technical
\end{abstract}

school and the beginning of the apprenticeships of the technical course in nursing, demonstrating that that moment is not fixed and nor demarcated. They also told ways of being young in groups that act in a different way. They discussed the time and the freedom, emphasizing them as the youth's routine is related to the school. That research made possible the reflection opportunity on the concepts on young, a lot of times crystallized in a society that rarely takes into account the voice of who more understand on himself, in other words, of the own subject that has the experience and it lives the youth.

KEYWORDS: Young, Technical School, Socio-poetics. 


\section{INTRODUÇÃO}

A juventude, as juventudes ou o sentimento ser jovem como se apresentam atualmente em muitos trabalhos, enquanto objetos de pesquisa, do ponto de vista analítico histórico, social e cultural têm levantado muitas interpretações e/ou abordagens sobre suas definições e implicações.

Segundo Adad (2011) para entender como se constituiu este sentimento "ser jovem" como categoria destacada da infância e do mundo adulto - é necessário entendê-lo como uma construção social e histórica, de cunho eminentemente moderno. Assim, de acordo com Ariès (1986), inicialmente a duração da infância era reduzida a seu período mais frágil, enquanto o filhote do homem ainda não conseguia bastar-se; de criancinha pequena, ela se transformava imediatamente em homem jovem, sem passar pelas etapas da juventude, que talvez fossem praticadas antes da Idade Média e que se tornaram aspectos essenciais das sociedades evoluídas de hoje.

Para Levi e Schmitt (1996), como as demais épocas da vida, quem sabe numa medida mais acentuada, também a juventude é uma construção social e cultural. Desse ponto de vista, a juventude se caracteriza por seu marcado caráter de limite. Com efeito, ela se situa no interior das margens móveis entre a dependência infantil e a autonomia da idade adulta, naquele período de pura mudança e de inquietude em que se realizam as promessas da adolescência, entre a imaturidade sexual e a maturidade, entre a formação e o pleno florescimento das faculdades mentais, entre a falta e a aquisição de autoridade e de poder.

No entanto, conforme esses autores, nenhum limite fisiológico basta para identificar analiticamente uma fase da vida que se pode explicar melhor pela determinação cultural das sociedades humanas, segundo o modo pelo qual tratam de identificar, de atribuir ordem e sentido a algo que parece tipicamente transitório, vale dizer caótico e desordenado. Essa "época da vida" não pode ser delimitada com clareza por quantificações demográficas nem por definições de tipo jurídico ou biológico exclusivamente, e é por isso que parece para eles, substancialmente inútil tentar identificar e estabelecer, como fizeram outros, limites muito nítidos.

Abramo (1994), entretanto, comenta que o termo juventude refere-se a uma faixa de idade, um período da vida em que se completa o desenvolvimento físico do indivíduo e uma série de mudanças psicológicas e sociais ocorre, quando este abandona a infância para processar a sua entrada no mundo adulto, quando passa por uma espécie de "moratória social", um período destacado que somente se configura em alguns grupos sociais, que podem manter seus filhos longe da via produtiva e social, com a finalidade de prepará-los para o futuro, onde o jovem teria um tempo de espera, para que só depois pudesse ser solto no mundo.

Sendo assim, para essa autora, a cristalização desse sentimento "ser jovem" não é algo universal, muito pelo contrário, varia de sociedade para sociedade ou dentro de uma mesma sociedade. Nas sociedades ditas primitivas, por exemplo, a passagem do universo infantil para o adulto é altamente institucionalizada e ritualizada, e os grupos etários têm funções e lugares definidos no sistema social.

Segundo Schindler (1996, p. 267), 
[...] a juventude também constitui em si um período da vida, objeto das atenções afetuosas da pedagogia; ao mesmo tempo, contudo, nós a consideramos com profunda desconfiança e a vigiamos, controlando-a por meio de toda uma série de instâncias burocráticas. Somente a sociedade dividida em classes da era industrial desenvolve ao máximo a dramaturgia da juventude enquanto portadora enfática de esperanças e de ameaças sociais latentes, ao passo que atribui à fase de tornar-se adulto as características de um fenômeno de tipo cultural, com conotações tanto negativas quanto positivas, mas de todo modo algo determinante.

Assim, as manifestações e expressões juvenis, ao longo do século XX e início do XXI, concorrem para compor o aparecimento público da juventude, tornando-se progressivamente percebida como sujeito social específico, com experiências, questões e formulações particulares, dadas pela sua condição etária e geracional. A percepção que se instaurou é de uma juventude em contraste com a ordem social dominante, sendo que a definição de juventude passa a estar marcada, sobretudo, pela negatividade ou pela indeterminação que produz. Cria-se, simultaneamente, um certo "estado de revolta" na juventude e, como diz Lapassade (1968), um certo "mal estar" generalizado na sociedade.

Pais (2003) amplia essa discussão ao dizer que os diferentes sentidos que o termo "juventude" tem tomado e as diferentes manifestações de sentido encontradas nos seus comportamentos cotidianos, nos modos de pensar e agir, em suas perspectivas sobre o futuro, nas suas representações e identidades sociais, compõem paradoxos analíticos importantes para a reflexão das culturas juvenis. $O$ desafio, como indica o autor, é perceber a juventude não apenas como um conjunto social cujo principal atributo é o de ser constituído por indivíduos pertencentes a uma mesma fase de vida, mas sim compreender as culturas juvenis como um conjunto social com atributos que os diferenciam. Portanto, uma passagem do campo semântico que toma a juventude como uma "unidade" para o que a toma como uma "diversidade", as juventudes.

Diante disso, para realizar esta pesquisa, foi necessário aceitar desafios, como: deixar de ver os jovens estudantes do curso técnico em enfermagem de um colégio técnico federal com uma visão encoberta pelas noções adquiridas através da mídia e da própria sociedade, a qual algumas vezes limita a entender os jovens apenas como um "grupo de risco" para uma multiplicidade de problemáticas construídas ao longo dos anos, para então considerar esses jovens como um grupo produtor de conhecimentos, capaz de indicar sua própria forma de perceber sua condição juvenil. Desse modo originou-se a seguinte questão problema: Como os jovens do curso técnico em enfermagem de um colégio técnico federal pensam sobre "o que é ser jovem?".

De acordo com pesquisa realizada pelo Ministério da Saúde (BRASIL, 2005), em nossa sociedade, circulam ideias sobre adolescência e juventude que se associam à noção de crise, desordem, irresponsabilidade; um problema social a ser resolvido, que merece atenção pública. O enfoque de risco, em particular, aparece fortemente associado a esses repertórios por meio de expressões como: gravidez de risco, risco de contrair o HIV, risco de uso de drogas ilícitas, risco de morte frente à violência. O risco generalizado parece, assim, definir e circunscrever negativamente esse período da vida, gerando expressões, ações e posturas absurdas em relação aos adolescentes. 
Nessas interpretações e/ou abordagens parece existir uma certa dificuldade em considerar os jovens como sujeitos de mudanças positivas, percebe-se que embora existam tentativas de possibilitar aos jovens a oportunidade de falar de si, o que realmente querem e quais são suas problemáticas, os espaços para esses diálogos são restritos. Desse modo, o presente estudo se constitui como parte do resultado de uma pesquisa sociopoética, desenvolvida como dissertação de Mestrado, em um Programa de Pós-Graduação em Educação.

A relevância dessa investigação esteve, em especial, na possibilidade das pesquisadoras se aproximarem desses jovens, ouvindo-os de outro modo, considerando-os como capazes de formular questões significativas, de propor ações relevantes, de efetuar uma relação dialógica com outros autores e de contribuir para ampliar os conhecimentos sobre a temática das juventudes. O objetivo foi conhecer os modos de pensar dos jovens de um curso técnico em enfermagem de um colégio técnico federal sobre "o que é ser jovem?". Esta pesquisa possibilitou adentrar em parte do universo pretendido, interferindo diretamente nas práticas docentes das pesquisadoras.

\section{PERCORRENDO OS CAMINHOS DA PESQUISA E CONSTRUINDO OS DADOS ATRAVÉS DA SOCIOPOÉTICA}

Abordagem filosófica de pesquisa e de ensino-aprendizagem, criada pelo filósofo e pedagogo francês Jacques Gauthier, "[...] a expressão sociopoética surge de um neologismo que une o latim socius - aquilo que é coletivo -, ao grego poiésis, que significa criação. Desse modo, o termo designa a construção coletiva do conhecimento." (SANTOS, 2013, p. 35). Como dispositivo de pesquisa (GAUTHIER, 2004a), tem origem nas vivências de Gauthier no movimento sindical de luta de um povo indígena situado na Kanaky, também denominada Nova Caledônia, no Pacífico, que lutou por sua independência contra o colonialismo francês (GAUTHIER, 2012). Segundo Santos et al. (2005), a Sociopoética é influenciada pela Pedagogia do Oprimido, de Paulo Freire; pela Análise Institucional, de René Lourau; pela Esquizoanálise, de Gilles Deleuze e Félix Guattari; pelo Teatro do Oprimido, de Augusto Boal; e pela Escuta Mitopoética, de René Barbier.

No Brasil, ganha uma nova dimensão a partir de implicações psicoafetivas, histórico existenciais, estruturais e profissionais, de Iraci dos Santos e de Jacques Gauthier que iniciaram a jornada intelectual acerca da sociopoética, nos anos 1990 e ao longo de quase duas décadas, novos estudos vêm sendo elaborados com base nos pressupostos filosóficos, teóricometodológicos e tecnológicos desta abordagem (SANTOS et al., 2013).

Conforme Gauthier (2003), a Sociopoética é uma prática filosófica, porque ela descobre os problemas que inconscientemente mobilizam os grupos sociais; favorece a criação de novos problemas ou de novas maneiras de problematizar a vida; favorece a criação de confetos, contextualizados no afeto e na razão, na sensualidade e na intuição, na gestualidade e na imaginação do grupo-pesquisador (sujeitos da pesquisa, também identificados como copesquisadores); favorece a criação de conceitos desterritorializados, que entram em diálogo com os conceitos dos filósofos profissionais.

O processo de uma pesquisa Sociopoética normalmente apresenta-se através de uma oficina de negociação, oficina de produção de dados pelos copesquisadores, sendo que após a produção, o facilitador (pesquisador oficial), particularmente, realiza sua própria análise da 
técnica(s) sociopoética(s) utilizada(s) na(s) oficina(s) de produção dos dados, em busca de linhas que perpassem o pensamento do grupo para o tema-gerador (nessa pesquisa foi "o que é ser jovem?" para jovens do curso técnico em enfermagem de um colégio técnico federal). Em seguida, o facilitador leva esses resultados analíticos para os copesquisadores, preferencialmente, de forma mais sintética, literária e comunicativa. Esse momento é chamado de contra-análise e permite aos copesquisadores conhecer, confirmar, retificar, reexaminar e, especialmente, contrapor-se às ideias do facilitador, tornando mais precisas as reflexões deste. Por fim, faz-se a análise filosófica, com base nas impressões dos copesquisadores acerca da contra-análise.

Desse modo, na Sociopoética, a pesquisa é realizada em grupo, motivo pelo qual a mesma foi escolhida para este trabalho, uma vez que as ações direcionadas aos jovens têm melhores resultados quando desenvolvidas numa perspectiva de grupo/coletividade. Além disso, a mesma ocorre em oficinas que utilizam dimensões da arte como dispositivos que causam estranhamento, o que torna possível a produção de conceitos heterogêneos, polifônicos, polissêmicos, metafóricos e mesmo inusitados sobre um tema-gerador.

Para compor o grupo-pesquisador, em maio de 2013, as pesquisadoras apresentaram a proposta à diretora do Colégio Técnico de Bom Jesus - CTBJ, vinculado à Universidade Federal do Piauí - PI, para que houvesse sua permissão para a tentativa de realização da pesquisa junto aos alunos do curso técnico em enfermagem da referida instituição. Em seguida, as facilitadoras foram às duas turmas dos referidos curso e colégio, explicaram aos alunos a pesquisa de forma clara e objetiva, sendo que 11 jovens demonstram interesse. Após a autorização de todos os seus pais e responsáveis, formou-se o grupo-pesquisador.

Iniciada a oficina de negociação, a sugestão do tema-gerador: "o que é ser jovem?" foi prontamente aceita, com entusiasmo, pelos jovens alunos. Em seguida, o acordo sobre os dias e horários das próximas oficinas foi realizado e iniciou-se um relaxamento ao som de uma música que inspirava tranquilidade. Após esse momento, os copesquisadores, sentados em colchonetes dispostos em círculo no chão, foram recortando retalhos de tecidos que coloriram o ambiente e deram roupas, cabelos, rostos e expressões a cartolinas em formato de corpos, as quais se transformaram em crachás.

Os copesquisadores optaram pelos seguintes nomes fictícios: Quadrilha, Margarida, Felicidade, Elena, Jukinha, Chris Rock Blue, Diversão, Peace, Açuceninha, Trapinho, Laura e deram início às apresentações se identificando como jovens que são sensíveis, não são rebeldes e por mais rebeldia que exista, por mais problemas que existam, têm um lado sentimental dentro de si, precisam de carinho, são felizes. Dito por eles, também são jovens que sentem a falta dos pais porque moram longe deles, gostam de quadrilha, de rock, de coisinhas delicadas, de se divertir, de sair com os pais, os amigos, a família. Têm um jeito de ser "street", porque são mais casuais, têm um lado brincalhão de fazer piadas com as coisas, com os momentos que acontecem na vida deles e pensam que todo jovem devia aceitar as diferenças uns dos outros e ter amor, liberdade e paz.

Para a oficina de produção dos dados foi escolhida a técnica sociopoética denominada Os bichos Jovens. Ao tempo em que essa oficina começou, o lanche foi servido, a música adentrou a sala e as brincadeiras começaram, colocando os corpos dos jovens em movimento e os preparando para um relaxamento. 
Durante o relaxamento, foi solicitado que os jovens fechassem os olhos, respirassem profundamente e gradativamente sentissem cada parte do corpo, até estarem preparados para uma viagem imaginária onde os mesmos se transformariam em bichos jovens. Durante o trajeto, os bichos jovens perceberam muitas cores e sons, passaram por obstáculos, encontraram aliados, subiram montanhas e alguns questionamentos foram sendo feitos, dentre eles: como você se sente sendo um bicho jovem? Que dificuldades o bicho jovem enfrenta? Qual a atitude do bicho jovem no buraco? O que ele fez no buraco? Como o bicho jovem saiu do buraco? Como é seu aliado? Com ajuda de quem o bicho jovem subiu ao topo da montanha? O que o bicho jovem encontra no topo da montanha? Quais as reações dele? O que ele pensa sobre o que é ser jovem?

Ao retornarem do relaxamento, os jovens pintaram suas respectivas viagens usando papéis, pincéis, tinta e muita imaginação. Além disso, esculpiram com massa de modelar o bicho jovem no qual haviam se transformado, e em seguida fizeram seus relatos orais. Em suas análises, as facilitadoras da pesquisa identificaram, dentre outros, os seguintes confetos produzidos pelo grupo-pesquisador: pássaro-borboletas jovens, jovens adultos, pássaro jovem, pássaros jovens em bando, tartaruga jovens, tigresa jovem.

Após a realização do próximo passo, a oficina de contra-análise - momento em que os facilitadores levam suas análises ao grupo-pesquisador, para que as mesmas sejam ratificadas, retificadas e complementadas - percebeu-se que os confetos se referem à (pássaro-borboletas jovens) jovens que se consideram marcados por um corpo em transformação, afirmam que se comportam como adultos (jovens adultos), no entanto eles divergem quanto a estarem ou não, preparados para serem adultos, problematizando o tempo de espera para a vida adulta. Essa problemática culmina em outra: jovem não tem identidade? São (pássaros jovens em bando) jovens que andam em bando, misturados, não se sabe quem é quem, nada é pouco, tudo é excesso, demonstrando que raramente estão sozinhos e que os bandos podem ser diferentes. $O$ confeto jovens tartaruga são aqueles jovens que agem esperando o tempo sem ansiedade e jovem tigresa é o jovem que corre feito gato, o tempo nunca é suficiente e nem eficiente, desse modo, criam a problemática da relação do jovem com o tempo. Em seguida, foi identificada, no pensamento do grupo-pesquisador, a linha de pesquisa: Jeitos de Ser Jovem.

\section{O SER JOVEM NAS LINHAS DO PENSAMENTO DOS JOVENS E O CONFRONTO COM OS ESTUDIOSOS DA TEMÁTICA JUVENTUDES}

Chegado o momento filosófico, que ora descreve-se, procurou-se confrontar o conhecimento produzido pelo grupo-pesquisador com reflexões teórico-filosóficas de outros autores ou correntes. O que chamou-se de "filosofia" não pode ser associado nem à reflexão, nem à contemplação, nem à comunicação:

Ela não é contemplação, pois as contemplações são as coisas elas mesmas enquanto vistas na criação de seus próprios conceitos. Ela não é reflexão, porque ninguém precisa de filosofia para refletir sobre o que quer que seja. [...] E a filosofia não encontra nenhum refúgio último na comunicação, que não trabalha em potência a não ser de opiniões, para criar o consenso e não o conceito (DELEUZE; GUATTARI, 1997, p. 14). 
Os autores supracitados afirmam ainda que as pessoas não podem conhecer nada por conceitos que não tenham sido criados por elas mesmas. Essa é a tarefa da filosofia: criar conceitos. O conceito tem sempre a verdade que lhe é possível em função das condições de sua criação, portanto, não se pode afirmar que haja um conceito melhor do que outro.

Foi com base nessa perspectiva que Gauthier (2004b) desenvolveu a noção de "confeto" (conceito + afeto) e de Sociopoética. Por meio dos dispositivos (técnicas artísticas), o grupopesquisador inventa novos conceitos e produz também metáforas. Essas, apesar de não se tratar propriamente de um conceito, promovem uma tensão produtiva num mundo que se apresenta pacífico e desproblematizado. Com base nas experiências práticas, observa-se que os grupos, por meio dos confetos, realizam deslocamentos no pensamento, em direção a novas possibilidades de criação. Além disso, o confeto envolve elementos poéticos e artísticos que fazem com que a Sociopoética se situe no entre-dois do saber e do sentir (SILVEIRA, 2004).

A criação do conceito se diferencia da metáfora, porque o conceito já não está ligado a uma ideia. O problema já se instaurou e é forçado a encontrar novas formas de dar conta dele. É aí que nasce o conceito. Ele vai se formando a partir de pedaços vindos de outros conceitos que respondiam a outros problemas, mas não dão conta do que se apresenta no presente. Um conceito é uma heterogênese, portanto (DELEUZE; GUATTARI, 1997).

A importância de criar conceitos reside na possibilidade de confrontar conceitos já constituídos, permitindo fazer surgir novas variações, operar vibrações, multiplicar possibilidades e suscitar novos acontecimentos. Com isso, aquilo que estava cristalizado começa a se tornar movimento. Desse modo, os confetos citados anteriormente surgiram de momentos de problematização e de criação em torno do tema: "o que é ser jovem?" para os jovens do curso técnico em enfermagem do Colégio Técnico de Bom Jesus - CTBJ. E, partindo dessas problemáticas, os pensamentos dos jovens se apresentaram na linha ou dimensão: Jeitos de Ser Jovem.

Nessa linha da pesquisa, inicialmente, os jovens se debruçaram na contra-análise sobre o confeto pássaro-borboletas jovens que são jovens de asas coloridas, com olhos grandes que podem ou não estar prontos para voar e tudo ver. Em suas falas, observou-se modos diferentes de pensar o ser jovem pássaro-borboletas, pois alguns jovens, como Chris Rock Blue, não se consideram prontos para voar e tudo ver, mas a caminho, e há aqueles que, como Trapinho, ainda estão começando e só depois pegam o voo. Exceto pela fala de Peace, de que "os jovens estão mais que prontos para voar e tudo ver", percebe-se nos outros enunciados a presença de representações instituídas historicamente sobre os jovens, de que devido a sua idade ou pela noção de ser em desenvolvimento podem viver fora da vida produtiva e social, com o intuito de preparar-se para o futuro e esperar um tempo para ser adulto, numa espécie de "moratória social" (ABRAMO, 1994; LEVI; SCHMITT, 1996).

Isso chama atenção porque esses jovens do curso técnico em enfermagem do CTBJ estão com idades entre 15 e 17 anos, estão fazendo um curso técnico profissionalizante e em sua maioria morando em outra cidade, longe de seus pais. Nesse contexto, se poderia pensar que esses jovens não passaram por uma moratória social? Se não passaram e já adentraram à vida produtiva e social, por que nem todos se consideram prontos para voar e tudo ver? Por que alguns disseram estar a caminho desse momento? Nesse sentido, para esses jovens do curso técnico em enfermagem do CTBJ, quando essa moratória social termina? 
Para problematizar essa dimensão do tempo de espera para o mundo adulto, o grupopesquisador criou ainda o confeto pássaro-jovem, que é aquele jovem bem diferente, desmanchando-se num fluxo fluido marcado por um corpo em transformação. Quando questionados na contra-análise sobre: em que situações o pássaro-jovem desmancha-se e tornase outra pessoa? A copesquisadora Jukinha disse: "acho que é quando você casa", Açuceninha afirmou: "a partir do momento em que você sai da casa dos seus pais para morar fora, você vai ter que virar um adulto de qualquer forma". Peace deu continuidade argumentando: "quando você vai para o estágio você também tem que ser um adulto, quando você veio de outra escola para o colégio técnico, você se tornou um adulto, porque é mais responsabilidade. Nós somos jovens com responsabilidade de adulto".

Para esses jovens, os ritos de passagem para o mundo adulto eram: casamento, saída da casa dos pais, a vinda de outra escola para o CTBJ e o início dos estágios do Curso Técnico em Enfermagem, demonstrando que a juventude não é um momento fixo e bem demarcado. Posto que muitos desses jovens já passaram por alguns desses ritos, eles mostraram que em seus modos de existir, muitas vezes passam por um Jeito de ser Jovem Adulto, ou seja, não há um único jeito de ser jovem e nem de se tornar adulto. Ao dizerem, por exemplo, que são jovens com responsabilidades de adulto, de certo modo, eles avaliam que aquilo que fazem é diferente do que o jovem considerado padrão pela sociedade faz.

Em lugar da expressão ritos de passagem, talvez fosse mais apropriado dizer ritos de consagração, ritos de legitimação, ou simplesmente, ritos de instituição e:

[...] falar em rito de instituição é indicar que qualquer rito tende a consagrar ou a legitimar, isto é, a fazer desconhecer como arbitrário e a reconhecer como legítimo e natural um limite arbitrário, ou melhor, a operar solenemente, de maneira lícita e extraordinária, uma transgressão dos limites constitutivos da ordem social e da ordem mental a serem salvaguardadas a qualquer preço, como no caso da divisão entre sexos por ocasião dos rituais de casamento. Ao marcar solenemente a passagem de uma linha que instaura uma divisão fundamental da ordem social, o rito chama a atenção do observador para a passagem (daí a expressão rito de passagem) quando, na verdade, o que importa é a linha. A rigor, o que esta linha separa? Um antes e um depois, é claro: o menino circuncidado e o menino não circuncidado [...] (BOURDIEU, 1996, p. 98).

Assim como Bourdieu (1996), a copesquisadora Peace problematizou o fato de o rito chamar a atenção do observador para a passagem e não para a linha, ao dizer que: "ninguém leva jovem a sério, todo mundo acha que jovem é só uma fase que vai passar, como se a gente hoje não fosse nada, ou é criança ou é adulto, e entre isso e outro, ninguém compreende".

De acordo com Bourdieu (1996, p. 100):

A instituição de uma identidade, que tanto pode ser um título de nobreza ou estigma ("você não passa por um..."), é a imposição de um nome, isto é, de uma essência social. Instituir, atribuir uma essência, uma competência, é o mesmo que impor um direito de ser que é também um dever ser (ou um dever de ser). É fazer ver a alguém o que ele é e, ao mesmo tempo, lhe fazer ver que tem de se comportar em função de tal identidade. Neste caso, o indicativo é um imperativo. A moral da honra constitui uma forma apurada da fórmula que 
consiste em dizer "é um homem". Instituir, dar uma definição social, uma identidade, é também impor limites [...].

Nesse caso, quando a copesquisadora Peace afirmou que "todo mundo acha que jovem é só uma fase que vai passar, como se o jovem não fosse nada", ela induz a pensar sobre o seguinte questionamento: estar na linha significaria não ter uma identidade? Jovem não tem identidade? A copesquisadora Peace também problematizou essa ideia ao dizer em outro momento da contra-análise: "Acho que todo jovem está à procura da identidade, até achar, a gente vai pegando um pouquinho de um, um pouco de outro, até achar o que você realmente gosta, o que você realmente é".

Segundo Bomfim (2006, p. 66), "os jovens buscam estabelecer sua identidade, ou seja, uma forma própria de comunicar-se consigo mesmo, com os outros e com o mundo, a partir de novas formas de sociabilidade". De acordo com Melucci (1992), o tema da identidade aparece como importante porque esta fase, ao ser caracterizada como de transição, pois nela se gesta um vir-a-ser, é, ao mesmo tempo, uma construção do presente, enquanto superação da infância, e em saída da infância. A busca da idade adulta remete para o jovem, quer individualmente ou em grupo, a questão do autorreconhecimento e de ser reconhecido. Assim, a identidade, individual ou coletiva, sempre pressupõe a dimensão da alteridade, ao ser uma categoria social e relacional.

Nesse contexto, Sposito (1996) afirma que se a questão da identidade é fundamental para a compreensão desse momento da vida humana, a tendência, no entanto, é considerá-la, no caso do jovem, a partir de estereótipos, quase sempre nascidos pela elaboração de uma imagem originada na mídia. Ao se referir ao universo juvenil, em geral, sem recortá-lo sob a ótica da classe social, a sociedade tem a tendência de considerar os jovens consumistas ou alienados. Se for recuperada a extração de classe, sobretudo para qualificar os alunos da escola pública, acrescenta-se, na maioria das vezes, o atributo de violentos ou marginais.

Também é interessante observar o quanto o modelo instituído de jovem - aquele que vive a moratória social e é separado do mundo adulto, atomizado - perpassa o imaginário do grupo, inclusive denotando fragmentação nesses rituais, de modo que não há um único ritual para o mundo adulto. Entretanto, nem sempre foi assim, Schindler (1996), por exemplo, comenta que no início da era moderna os ritos de passagem eram bem definidos e os jovens e sua "rebeldia" tinham um lugar nesta sociedade, na verdade, ela já era esperada. Só depois é que há uma atomização do jovem - moratória social - quando eles passam a ser separados do mundo, para só depois serem soltos.

Inclusive, para que fosse constituída e demarcada a infância e adolescência como um momento destacado do mundo adulto, foram inventados os espaços da escola e da família. Segundo Ariès (1986, p. 11), "a escola substituiu a aprendizagem como meio de educação. Isso quer dizer que a criança deixou de ser misturada aos adultos e de aprender a vida diretamente, através do contato com eles". Ariès (1986, p. 12) afirma ainda que:

A família começou então a se organizar em torno da criança e a lhe dar uma tal importância, que a criança saiu de seu antigo anonimato, que se tornou impossível perdê-la ou substituí-la sem uma enorme dor, que ela não pôde mais ser reproduzida muitas vezes, e que se tornou necessário limitar seu número para melhor cuidar dela. 
Outra dimensão interessante dos Jeitos de Ser jovem trazida pelos copesquisadores está no confeto pássaros jovens em bando, que são os jovens que andam em bando, misturados, não se sabe quem é quem, nada é pouco, tudo é excesso que na contra-análise foi discutido mediante a seguinte questão: O que pode pássaros jovens em bando?

Nos depoimentos, percebe-se Jeitos de Ser Jovem em bando, pois os copesquisadores demonstram que raramente estão sozinhos. No entanto, esses bandos são diferentes, de acordo com Felicidade: "tem aquele bando que pode se juntar para bagunçar mesmo, bagunçar na aula, mas tem os mais calmos, que se juntam para assistir filme ou até para falar besteira". Para Peace: "um bando nunca se junta para ficar triste, sempre se junta para ficar mais alegre, para esquecer tudo, para zoar, ir à festa".

De acordo com Bomfim (2006, p. 66), os jovens "não querem ficar sozinhos e por isso buscam agregar-se a outros jovens, não em formas gregárias tradicionais em que há presença de tutores, mas em grupos nos quais eles e elas são os(as) protagonistas".

Os copesquisadores também demonstraram que o Jeito de Ser Jovem em bando é potente, pois de acordo com Felicidade: “o jovem tem mais força quando está num bando, porque dá mais coragem". Além disso, conforme Chris Rock Blue "não se vê um grupo chorando, nem falando de problemas, porque o problema é íntimo e os jovens não confiam em todos do bando, somente em alguns, os amigos de verdade são poucos". Nesse contexto, os copesquisadores levantam a ideia de grupo, das sociabilidades presentes nas amizades, nas festas, no excesso.

De acordo com Dubet e Lapeyronne (1992), é preciso considerar que o momento da juventude é rico em manifestação da sociabilidade, sendo as dimensões expressivas muito mais fortes do que as orientações de caráter instrumental. Ou seja, as formas coletivas e grupais que surgem, às vezes de modo fluido e fragmentário, tendem a incidir muito mais para a manifestação de um desejo de ser, daí a sua natureza expressiva, do que para a lógica racionalinstrumental voltada para a consecução de algum fim imediato.

Segundo Sposito (1996, p. 100), “[...] não ocorre, por acaso, o fato de que o mundo da produção cultural e das artes, em especial, a música, a poesia, o teatro e a dança, ocupam grande parte do universo de interesse juvenil".

O grupo-pesquisador também problematizou essa linha de outro modo, ao mostrar Jeitos de Ser Jovem fazendo relações com o tempo, quando produziram os confetos jovens tartaruga, que são aqueles jovens que agem esperando o tempo sem ansiedade, e jovem tigresa, que corre feito gato, o tempo nunca é suficiente e nem eficiente. E quando questionados: É o jovem que faz a hora? Ou a hora já vem marcada? Qual o tamanho da liberdade do jovem? Os copesquisadores mostraram um Jeito de Ser Jovem problematizando o tempo e a liberdade.

Em relação ao tempo, eles concordam com Jukinha, quando ela disse: "depende, na escola você tem que acordar $6 \mathrm{~h}$, fazer o café da manhã, se você atrasar 2 minutos você perde o ônibus". Segundo Açuceninha: "o jovem faz a hora no final de semana e podem dividir seu tempo, mas escolher a hora de tudo não". Evidenciou-se, nesse momento, o quanto a rotina desses jovens está relacionada à escola, uma vez que fazem o ensino médio pela manhã, o técnico em enfermagem à tarde e muitas vezes ainda precisam frequentar os estágios do curso profissionalizante à noite. 
Esse contexto conduziu as facilitadoras a lembrar dos versos: "Vem, vamos embora/ Que esperar não é saber/ Quem sabe faz a hora/ Não espera acontecer" da música "Pra não dizer que não falei das flores", composta e interpretada por Geraldo Vandré, que ficou em segundo lugar no Festival Internacional da Canção, de 1968 e, depois disso, teve sua execução proibida durante anos, pela ditadura militar brasileira. A canção que incitava o povo à resistência levou os militares a proibi-la, usando como pretexto a "ofensa" à instituição contida nos versos "Há soldados armados, amados ou não / Quase todos perdidos de armas na mão / Nos quartéis lhes ensinam uma antiga lição / de morrer pela pátria e viver sem razão". Não seria controverso em um tempo de democracia, a escola fazer o tempo dos jovens? Essa também não seria uma forma da escola vigiar os jovens?

Atravessando a problemática do tempo, os jovens falaram da liberdade ao dizerem que não sabem o tamanho da mesma e que depende dos pais de cada um. Para a copesquisadora Jukinha, "tem muitos jovens que querem morar sozinhos, porque não aguentam mais morar com os pais, querem ser livres", mas para ela "é bom morar com os pais, porque quando o jovem vai morar sozinho, além de ter hora para acordar no final de semana, tem que ir ao supermercado, varrer a casa, lavar louças". No entanto, a copesquisadora Felicidade disse que mora com os pais e também precisa fazer tudo isso. Por sua vez, a copesquisadora Jukinha argumentou que "quando o jovem mora com seus pais, se acontecer alguma coisa, ele sabe que os pais vão fazer por ele", no caso dela, não tem isso, ela precisa fazer. Desse modo, ao contrário de muitos jovens que pensam que serão mais livres ao sairem de casa, a copesquisadora Jukinha mostrou um Jeito de Ser Jovem livre diferente do que costuma ser habitual, para ela, a liberdade seria maior se estivesse em casa. A copesquisadora Elena, que mora com os pais, revelou ainda que "a vida está boa e gosto da liberdade restrita".

O copesquisador Chris Rock Blue problematizou ainda mais essa discussão ao dizer: "Ninguém é totalmente livre, porque o mundo é cheio de regras, ninguém tem toda liberdade de fazer o que quer".

Desse modo, o grupo-pesquisador mostrou um Jeito de Ser Jovem que não é totalmente livre. Peace acha que sempre haverá a lei e a ética, e dá um exemplo: "o jovem não vai sair com um carro a $200 \mathrm{~km} / \mathrm{h}$ numa rua". Felicidade complementa esse pensamento ao dizer que "não é porque a pessoa é livre para fazer aquilo, que ela vai fazer. Às vezes, o jovem tem a liberdade para fazer aquilo, mas não faz porque sabe que é errado" e considera ainda que liberdade para fazer aquilo, ela tem. Nesse caso, o pensamento de Felicidade é diferente do pensamento de Laura, que afirma que "sempre haverá horário para tudo, independentemente do que for fazer; então, o jovem nunca terá liberdade". Nessa discussão, nota-se que esses jovens reconhecem a existência de regras na sociedade e não sentem o desejo de transgredi-las, porque sabem que é errado.

Os copesquisadores ampliaram essa discussão questionando o "seguir as regras" e a relação com a liberdade, quando criaram o confeto borboleta jovem, que é o jovem livre para voar, porque tem mais liberdade. No caso da borboleta jovem a liberdade é boa porque as dificuldades buraco jovem são aquelas em que o jovem vive sob pressão, sob mandados, e isto, para quem está começando a vida, não é fácil. Diante da pergunta: Que pessoas ou situações podem exercer pressão a um jovem, a ponto de impedir a liberdade? O grupo-pesquisador concordou com Jukinha quando ela revelou: "as regras da escola exercem pressão a um jovem, porque o aluno tem que tirar nota boa, comportar-se, não pode responder aos professores, deve 
assistir a todas as aulas". Nesse caso, haveria uma tentativa da escola e dos pais em criar um Jeito de Ser Jovem docilizado? E nesse contexto, esses jovens estariam docilizados? Entendeu-se que os confetos borboleta jovem e buraco jovem denunciam um corpo desejoso de ser livre e autônomo frente a uma vida que não é fácil por estar sempre à mercê de ordens vindas de todas as instâncias, devido estar começando envolvido em mandados de toda ordem.

Desse modo, os resultados permitiram perceber e conhecer os modos de pensar dos jovens de um curso técnico em enfermagem de um colégio técnico federal sobre "o que é ser jovem?", possibilitando uma reflexão sobre: até que ponto a escola bem como os professores influenciam os jeitos de ser jovem?

\section{CONSIDERAÇÕES FINAIS}

Os jovens problematizaram a dimensão do tempo de espera para o mundo adulto, mostrando que não há um único modo de ser jovem e nem de se tornar adulto, pois para eles os ritos de passagem eram: casamento, saída da casa dos pais, o ingresso em um colégio técnico federal e o início dos estágios do curso técnico em enfermagem, demonstrando que esse momento não é fixo e nem demarcado. Eles também apresentaram em seus relatos, jeitos de ser jovem em bandos que agem de modo diferente, uns se reúnem para bagunçar, outros são mais calmos e se reúnem para assistir filme ou até para falar besteiras, desse modo trouxeram a ideia das sociabilidades, presentes nas amizades, nas festas, no excesso. Além disso, problematizaram o tempo e a liberdade, resaltando o quanto suas rotinas estão relacionadas à escola, apontando jeitos de ser livres diferentes do que eles consideram habitual entre os jovens, manifestando, por exemplo, que se sentiriam mais livres se morassem com os pais.

Essa pesquisa possibilitou a oportunidade de reflexão sobre os (pre)conceitos em relação ao ser jovem, conceitos estes muitas vezes cristalizados numa sociedade que raramente leva em consideração a voz de quem mais entende sobre si mesmo, ou seja, do próprio sujeito que tem a experiência e vivencia a juventude. A intenção desse estudo foi de provocar movimento, induzir a descristalização e abrir possibilidades para que outras pessoas também se interessem pelo tema em questão.

\section{REFERÊNCIAS BIBLIOGRÁFICAS}

1. ABRAMO, H. W. O estilo monta o espetáculo. Cenas Juvenis: Punks e Darks no espetáculos urbanos. São Paulo: Página Aberta, 1994.

2. ADAD, S. J. H. C. Corpos de Rua: cartografia dos saberes juvenis e o sociopoetizar dos desejos dos educadores. Fortaleza: Edições UFC, 2011.

3. ARIÈS, P. História Social da Criança e da Família. 2. ed. Rio de Janeiro: Guanabara Koogan S.A., 1986.

4. BOMFIM, M. C. A. Agregação de juventude: múltiplos olhares. IN: BOMFIM, M.C.A: Juventudes, Culturas de Paz e Violências na Escola. Fortaleza: UFC, 2006.

5. BOURDIEU, Pierre. Economia das trocas linguísticas. São Paulo: Edusp, 1996.

6. BRASIL. Ministério da Saúde. Secretaria de Atenção à Saúde. Marco legal: saúde, um direito de adolescentes. Brasília: Ministério da Saúde, 2005. 
7. DELEUZE, G., GUATTARI, F. Mil platôs: capitalismo e esquizofrenia. v. 4. Rio de Janeiro: Editora 34, 1997.

8. DUBET, F., LAPEYRONNIE, D. Les quartiers d'exil. Paris: Seuil, 1992.

9. GAUTHIER J. Notícias do rodapé do nascimento da sociopoética. Mimeografado, 2003.

10.

A questão da metáfora, da referência e do sentido em pesquisas qualitativas: 0 aporte da sociopoética. Rev. Bras. Educ., Rio de Janeiro , n. 25, Apr. 2004a. Available from <http://www.scielo.br/scielo.php?script=sci_arttext\&pid=S1413-24782004000100012\&lng=e n\&nrm=iso>. access on 22 Jan. 2014. http://dx.doi.org/10.1590/S1413-24782004000100012.

11.. o oco do vento: metodologia da pesquisa sociopoética e estudos transculturais. Curitiba: CRV; 2012.

12. _. Trilhando a Vertente Filosófica da Montanha Sociopoética: a criação coletiva de confetos. In: Prática da pesquisa nas ciências humanas e sociais: aplicação da abordagem sociopoética. São Paulo: Atheneu, 2004b.

13. LAPASSADE, G. Os rebeldes sem causa. Sociologia da Juventude III: a vida coletiva juvenil. Rio de Janeiro: Zahar, 1968.

14. LEVI, G., SCHMITT, J. (Org.). História dos jovens I: da antiguidade à era moderna. São Paulo: Companhia das Letras, 1996.

15. MELUCCI, A. II gioco dell'lo. Milão: Saggi/Feltrinelli, 1992.

16. PAIS, J. M. Culturas Juvenis. Lisboa: Imprensa Nacional / Casa da Moeda, 2003.

17. SANTOS, I. et al. Contribuições da sociopoética à produção científica sobre cuidar em enfermagem: revisão integrativa de literatura. Revista Eletrônica de Enfermagem. [Internet]. v. 15, n. 1, p. 243-52, jan/mar. 2013. http://dx.doi.org/10.5216/ree.v15i1.20888

18. _. et al (Org.). Prática de pesquisa nas ciências humanas e sociais: abordagem sociopoética. São Paulo: Atheneu, 2005.

19. SANTOS, M. C. S. Páginas Sociopoéticas: deslizando nas ideias e nos conceitos de jovens sobre leitura. 2013. 151 f. Dissertação (Mestrado em Educação) - Programa de PósGraduação em Educação da Universidade Federal do Piauí, 2013. Disponível em: <http://www.ufpi.br/subsiteFiles/ppged/arquivos/files/Disserta\%20SANTOS,\%20Maria\%20d a\%20Conceicao\%20de\%20Souza.pdf>. Acesso em: 26 set. 2014.

20. SHINDLER, N. Os tutores da desordem: Rituais da cultura juvenil nos primórdios da era moderna. In: LEVI, G., SCHMITT, J. (Org.). História dos Jovens. São Paulo: Companhia das Letras, 1996.

21. SILVEIRA, L.C. Do corpo sentido aos sentidos do corpo: sociopoetizando a produção de subjetividade. Programa de pós-graduação em enfermagem, 2004. 169f. Tese (Doutorado em Enfermagem). Universidade Federal do Ceará - UFC, 2004.

22. SPOSITO, M. P. Juventude: crise, identidade e escola. In: DAYRELL, J. Múltiplos Olhares. Belo Horizonte: UFMG, 1996. 